\title{
PROPOSTA DE ANTEPROJETO DE LEI ${ }^{\text {(1) }}$
}

Instimi o Sistema de Carreirn io Servidor Civil da Uniāo, fixa as stuas diretrizes, do ouras providências.

() PRESIDENTE I)A REPÚBLICA, faço saber que o Congresso Nacional decreta e eu sanciono a seguinte I cei:

\section{CAPÍTULO I \\ Das Dispociçōes Preliminares}

Arl. Io - Fíca instituído a sistema de carreira na administração púhlica federal destinado a organizar os cargos públicos de provimento efetivo $\mathrm{cm}$ planos de carreira, fundamentados nos princípios de qualificaçāo profissional e de desempenho, com a finalidade de assegurar a continuidade da açāo administrativa e a eficiência do serviço público.

Art. 2:-Os caúgos da administraçāo pública federal dircta das autarquias, inclusive as de regime especial e das fundaçōes públicas, serāo organizados e providus em carreiras. observadas as diretrizes estabelecidas nesta Lei.

\section{CAPÍTULO IT \\ Da Composiçāo da Carreira}

An. 3- - As carreiras serāo organizadas em classes de cargos, dispostas de acordo com a natureza profissional e complexidade de suas atribuiçōes, guardando correlaçāo com as finnalidades do órgāo ou entidade.

Paráarafo único - As carreiras poderāo compreender classes cargos do mes-

(1) P'ublicado no Diário Oficial da Repuiblica Federativa do Hrasil, [3rasília, v. I27. n² I56, p. 13995, Seçäo I. 16200,1989

R. Serv. Publ. Brasília, II7 (1): 29-36, jun./set. I989 
mo grupo profissional, reunidas em segmentos distintos, de acordo com a escolaridade exigfvel para o ingresso, nos níveis básico, médio e superior.

Art. 4- - O Cargo público como unidade básica da estrutura organizacional દ o conjunto de atribuiçōes e responsabilidades cometidas um funcionário.

Art. 50 - As carreiras serão estruturadas en classes e cstāo desđlobradas em padrōes, correspondentes aos respectivos níveis de vencimento.

\$ 1 o - Classe é a divisão básica da carreira agrupando os cargos da mesma denominação, segundo o nível de atrihuiçōes e responsabilidades.

$\$ 2^{2}-$ Do conteúdo das classes constará a descriçāo das atribuiçôes, de acordo com o grau de complexidade e responsabilidade, necessário para o desempenho, inclusive das funçōes de direçāo, chefīa, assessoramento e assistência.

Art. $6^{2}-$ As carreiras serāo constituídas distintamente pelos cargos cujas atividades:

1 - sejam típicas, exclusivas e permanentes do Estado e exijam qualificaçāo profissional específica;

II - encontrem correspondência no setor privado, podendo essas atividades ser de naturcza finalística, sistêmica ou comum a todos os órgãos ou entidades.

Parágrafo único - As carreiras de que trata o inciso Il desse artigo, poderẫo compreender cargos orientados para uma ou mais especialidades.

An. $7^{2}$ - Integrarāo os planos de carreira, as funçōes de direçāo, chefia, assessoramento e assistência, em correlaçāo com os cargos das carreiras, correspondendo:

1 - as de direçāo, aos cargos situados nos nívcis hicrárquicos superiores:

II - as de chefia aos cargos situados nos nívcis internediários e iniciais:

111 - as de assessoramento, aos cargos que exijam desempenho de atividades qualificadas e complexas, nos níveis superior e intermediário: e

IV - as de assistência, aos cargos que exijan desempenho atividades simples e auxiliares, em todos os níveis.

\$ lo - As funçŏes de que trata este arigo serāo exercidas pelos ocupantes dos cargos de camcira, mediante designaçāo por acesso observados o processo selelivo, critérios de rotatividade e sistema de avaliaçāo especílico.

$\$ 2^{\circ}$ - Para o cxercício dessas funçōes serão. ainda, exigidos no mínimo, os seguintes requisitos:

a) - perfil profissional correspondente às exigências do cargo:

b) - desempenho nos cargos anteriores de direção, chelía, assessoramento e assistência, excetuados os casos de primeira investidura:

c) - fomeçāo gerencial espccífica.

\$ 3ำ - No âmbito de cada b́rgāo ou entidade será estabelecida correlação enire a classe e o nível das funçöes de direçāo, chefia, assessoramento e assistência.

\section{CAPI'TULO III}

\section{In Ingresso}

Art. 8 - Os cargos de provimento efetivo no serviço público ferleral săo 
acessfveis aos hrasileiros e o ingresso dar-se-á no primeiro padrāo da classe inicial do respectivo nível da carreira, atendidos requisitos de escolaridade e habilitação em concurso público de prova ou de provas e títulos.

$\$ 1$ - Fxcepcionalmente, no nível supcrior, poderá ocorrer ingresso para o primeiro padrão da classe seguinte e à inicial, até o limite máximo de vinte por cento dos cargos da respectiva classe, observado o disposto neste artigo.

$\$ 2$ - Constituem requisitos de escolaridade para o ingresso nos cargos:

a) - de nível hásico, comprovante de escolaridade até a 8 - série do 1 grau:

b) - de nível médio, certificado de curso de $2^{\circ}$ grau e habilitaçāo legal, quando se tratar de atividade profissional regulamentakla.

c) - de nivel superior, diploma de curso superior.

Art 92 - O concurso púhlico será realizado cm duas etapas ambas de caráter eliminatório, compreendendo:

I - na 1 a ctapa - provas ou provas e títulos:

11 - na 2- elapa - programa de formaçāo inicial.

§ I - A matrícula do candidato no programa de fornaçāo inicial se dará até o limite de vagas determinado no edital de abertura do concurso público.

$\$ 2^{\circ}-$ Os candidatos aprovados na primeira etapa do concurso matriculados no programá de formação inicial perceberāo ajuda financeira nos limites c condiçōes a serem fixadas em regulamento, salvo op̧̧āo pelo vencimento ou salárin e vantagens do cargo ou emprego efetivo, se pertencentes à administração direta, indireta ou fundacional.

Art. 10 - Concluídas as duas etapas do concurso e homologado os seus resultados, serāo nomeados os candidatos habilitados, obedecido a ordem de classificaçāo estabelecida no respectivo regulamento.

Art 11 - O funcionário uma vez nomeado, cumprirá estágio probatório, de acordo com o Estaruto dos Funcionários Púhlicos Civis da Uniāo e na forma desta Lei.

Art. 12 - As pessoas portadoras de deficiência serāo nomeadas para as vagas que thes forem destinadas, observada a exigência de escolaridade, apticlāo e qualificaçâo profissional definidas em regulamento específico.

\section{CAPÍTULO IV \\ Do Desenvolvimento, Da Avaliaçāo de Desempenlın e Da Qualificaçāo Profissional}

\section{Seçāo I \\ Do Desenvolvimento}

Arr. 13 - O desenvolvimento do funcionário na carreira ocorrerá mediante progressāo, promoção, acesso c ascensāo, a seguir definido:

I - Progressāo é a passagem do funcinnário de um padrāo para o seguinte, 
dentro da mesma classe, obedecidos os critérios especificados para a avaliação de desempenho e o tempo de eletiva permanência na carreira.

1 - Promoção é a passagem do funcionário de uma classe para imediatamente superior do respectivo gripo da carreira a que pertence obedecidos os critérios de avaliaçāo de desempenho e qualificação prolissional.

11 - Acesso é a investidura do funcionário na funçāo de direção, chefia, assessoramento e assistência, segundo os critérios estabelecidos no art. $7^{2}$ desta Lei.

Ant. 14 - Ascensāo é a passagem do funcionário da última classe de nível básico para a prineira do nível médio e da última deste para a primeira do nível superior, na mesma carreirá.

\& 1\% - A ascensão depende de habilitaçāo em concurso público na forma do artign 92 desta Leî.

$\$ 2$ - A terca parte das vagas existentes, fixadas no edital de concurso, será reservada para os funcionários da carseira em que promove a ascensão, os quais terāo classificaçāo distinta dos demais concorrentes

$\$ 30$ - As vagas referidas no parágrafo anterior que nāo foram providas serăo automaticamente destinadas aos demais candidatos habilitados no concurso.

Art. 15 - Para efeito de desempate a ser procedida na progressão, promoçāo c acesso serão considerados sucessivanente os seguintes critérios:
a) classificação em concurso público:
b) naior tempo de serviço na classe:
c) maior tempo de serviço na carreira:
d) maior tempo de serviço público federal;
e) naior tenpo de serviço público em geral:
0 o de maior prole: e
g) o mais idoso.

\section{Seção II}

\section{I)a Avaliaçāo de Desempenho}

Art. 16 - A avaliação de desempenho no estágio probatório, progressão, na promoçâo e no acesso levará em conta, dentre outros, seguintes fatores:

1 - produtividade:

II - iniciativa:

11 - cooperaçāo:

IV - qualidade do trabalho:

$V$ - responsabilidade.

Ar1. 17 - Na avaliaçāo de desempenho serāo adotados modelos que atenderāo a natureza das atividades desempenhadas pelo funcionário $\mathrm{c}$ as condiçōes em que serāo exercidas, observadas as seguintes características fundamentais:

I - objetividadc c adequaçāo dos processos e instrumentos de avaliaçāo ao conteúdo ocupacional das carreiras:

I] - periodicidade: 
Ill - contribuiçẫo do funcionário para consecuçāo dos objecivos do órgão ou cnliclade:

IV - comporamento observável do funcionário;

V - conhecimento, pelo funcionário, do resultado da avaliaçāo.

Art. 18 - Scrá instituída en cada órgão ou entidade uma comnissão de caráater permanente com ofim de avaliar os funcionários de carreira.

\$ te - A comíssāo será constitú́la de, no máxinı, scle menbros e presidida pelo titular de cargo de segunda linha hierárcjuica do órgāo ou entidade e integrada pelos dirigentes dos escalōes superiores, inclusive o de pessoal, çue funcionará cono secretário-executivo.

\$ 2 - Poderāo ser adotados processos de auto-avaliaçāo do funcionário ou da avaliaçāo con participaçāo de inteğrantes de sua carreira.

Ar1. 19- Observado o disposto nos artigos 16 e 17, o regulamento disciplinará os procedimentos da avaliação de descmpenho, podendo adotar características atdicionais com o lim de atender as necessidades especílicas dos órgãos ou entidades.

\section{Seçāo lll \\ l)a Qualificação Profissional}

Art. 20 - A qualificaçāo profissional, como base da valorizaçāo do funcionário, compreenderá programa de formaçāo inicial, constituído de segmenros teó ricos e próticos e programas regulares de aperfeiçoamento e especializaçāo, inclusive de natureza gerencial, para fins de promoçāo e atcesso.

Art. 21 - A çualificaçāo proftessional de que trata o ardigo anterior será planejada, organizada e executada de forma integrada ao sistema de carreira e atenderí, quanto:

I - à formaçāo inicial - preparação dos candidatos para exercício das atrihuiçōes dos cargos das carreiras transmirindo-lhes conhecimentos, métodos, técnicas c habilidades adequadas: c

11 - progranas regulares de aperfeiçoamento e especializaçāo, complcmenta(̧̃ô e arualizaçâo da formação inicial, habilitando o funcionário para o desempenho eficiente das atribuiçōes increntes à respectiva classe c à classe imediatamente superior, inclusive para o cxercício das funçōes de direçāo, chefia, assessoramento c assistência.

\$ I - Quando o funcionário aringir, no mínino, cinqüienta por cento dos padróes da classe a que pertence, poderá se inscrever nos casos regulatres de qualificação profissional, para lins de promoçāo

$\$ 2-O$ regulamento estabelecerá:

a) as áreas básicas de conhecimenuo, as habilidades e récnicas necessárias, inclusive de gerência:

b) os critérios de avaliação dos programats de qualificaçāo profissional:

R. Scrv. Pub]. [3rasília, 117 (1): 29-36, jun./set, 1989 
c) a duraçāo dos cursos de aperfeiçoamento e especializaçāo para promoçāo e acesso.

Ar. 22 - Os cursos regulares de qualificação profissional poderâo ser realizados pelas escolas instiuidas com este fim ou pelas unidades próprias dos órgāos do sistema de pessoal civil.

Art. 23 - Alén dos cursos regulares poderão ser oferecidos outros que aprimorem o desempenho funcional.

Arr. 24 - Será estabelecida cn regulamento a duraçāo mínima para programa de formaçāo inicial que. para os níveis médio e superior carreiras de que trata o artigo $6^{\circ}$, inciso I, desta Leí, será de três a seis meses, respectivamente.

\section{CAPÍTULO V}

\section{Da Organizaçảo dos Quadros de Pessoal}

Art. 25 - Os quadros de pessoal dos órgāos ou entidades de que trata o art. 22 serăo organizados de acordo con as diretrizes desta Lei e deverāo comprecuder:

I - os cargos cm comissão de livre nomeação e exoneração:

II - os cargos de provimento efetivo integrantes das carreiras:

III - as funçōes de direçāo, chefia, assessoranento c assistência.

Parágrafo único. Os quadros de pessoal especifı́carāo as alribuiçōes dos cargos e funçốes e fixarão o seu número pelas classes de cada carreira.

Art. 26 - São os seguintes ns cargos de live nomeaçāo e exoncraçāo que integrarāo os quadros de pessoal da administração pública federal:

I - Advogado-Geral da União:

I] - Secretírjo-Cieral:

lI] - Dirigente superior de autaruguia e fundação pública:

IV - Chefe de Gabinete de Ministro de Estado:

V - Assessor de Ministro de Estado no percentual de até vinte por cento.

Art. 27 - Constará, ainda, como Anexo ao quadro de pessoal, relaçăo dos cargos em extinçāo, constituída pelos funcionários nāo optantes pelo sistema de carreira ou inabilitados no concurso de efetivaçāo, a que se relere o artigo 36 desta Lei.

\section{CAPÍTILO V']}

\section{I) Administração do Sisıema de Pessoal}

Art. 28 - O Poder Executivo manterá o Sistema de Pessoal (ivil, cabendo ao órḡa central coordenar, supervisionar e oricntar a implantaçân c a administraçăo dos planos de carreiras a seren propostos pelos órgāos ou entidades de que trata o artigo $2^{2}$ desta Lci. 
Parágralo único - O órgâo central expedirá as normas e instruçōes necessárias a uniformidade do Sistenát.

Art. 29 - Caberá ans órgāos de pessoal a administraçāo de planos de carreira, e aos órgāos setoriais, cumulativamente a coordenaçầo e orientação das uniclades seccionais.

Parágrafo único - Os brgãos setoriais poderão propor a alteraç̃̃o das atribuiçōes das carteiras, as especificaçōes de suas classes, planos de desenvolviлento, a avaliação de desempenho e qualificaçāo profissional, c outras medidas que permítam o aperfeiçoamento do Sistema Pessoal Civil.

Art. 30 - Objetivando a racionalizaçāo e a continuidade de suas atividacles, cada órgâo ou entidade estabelecerá cronograna anual provimento de carẹos de carteira, de acordo com suas disponibilidades orçanentárias.

Art. 31 - Será adnitida a transferência de funcionário de carreira ou de quadro em extinçāo, na forma do que dispuser o Estatuto dos Funcionários Civis dà Úniāo.

\section{CAPÍTULO VII}

\section{Ua Implantaçāo dos Planos de Carreira}

Art. 32 - A implantação dos planos de carrcira será precedida de:

I - revisão c racionalizaçāo da estrutura organizacional hem assim das arividades sistemicas ou comuns:

II - redimensionamento da força de trabalho:

III - extinçāo da māo-de-obra indiresa, existente para cxercício das arividades próprias aos cargos de carreira.

Art. 33 - Os ocupantes de cargos ou empregos pertencentes a quadros ou tahelas permanentes dos atuais planos de cargos dos órgāos e entidades a que se refere o artigo 20 desia Lei, poderão ingressar para transposiçāo nos carg̣os de carreira dos planos de que trata esta Lei mediante npẹāo e desde que:

I - estejam lotados ou en exercício nos órgăos ou entidades ná data da publicação desta Lei:

II - haja compatibilidade das atribuiçōes do cargo ou empresa ocupado com aquelas dos cargos da carreira: e

IlI - preenchan os demais requisitos exigidos para ingresso na carreira.

\$ 1ㅇ- - A transposição dos funcionários para os cargos de carseira, far-se-á até o limite das vagas existentes, obedecida a seguinte ordem de prioridade:

a) ingresso por concurso públíco:

b) realizaçāo de concurso para ascensão funcional:

c) realizaçāo de processo seletivo para a clientela secundária ou ğeral:

d) estabilidade no serviço público federal, na forma do disposto no arigo 19 do Ato das Disposiçōes Constitucionais Transitórias:

$\$ 2^{0}$ - Os funcionários nāo enquadrados nas alíneas constantes do parágrafo 
anterior, terāo seu ingresso nos cargos de carreira subordinado à habilitaçāo prévia em concurso.

\$ 3ำ- No caso de cmpate na classilicaçāo do funcionário, scrāo utilizados os critérios de desempate previstos no artigo 15 dessa Lei.

Art. 34 - O ingresso ou transposiçăo de que trata o artigo anterior, será disciplinado em regulamento próprio.

Ar1. 35 - Os ocupantes de cargos ou empregos nāo alcançados pelo disposto no artigo 33 e lotados ou em exercício na administraçāo direta, autárquica ou fundacional, em 5 de outubro de 1988 , e que permaneceram nesta condiçāo até a data da publicaçāo desta Lei, serāo inscritos de ofício em concusso, a ser realizado no prazo máximo de um ano, uma vez hahilitados, poderāo ingressar nos cargos de carteirá, obcervados os requisitos dos incisos 11 e III do artigo 33 desta Lei.

Art. 36 - Os funcionários não optantes peln plano de carreira e os inabilitados no eoncurso a que se refere o artigo anterior, integrarāo os quadros em extinção, sem prejuízo das progressōes funcionais que fazem jus nos respectivos planos.

\section{CAPÍTULO VIII}

\section{Das Disposiçōes Gerais Transitórias}

Art. 37 - Os planos de carreira serāo instituídos exclucivamente pelas normas estabelecidas nesta leei, nāo prevalecendo para nenhum efeito as normas aplicadas aos atuais planos de cargos.

Art. 38 - Será procedida a revîsāo dos proventos e pensōes mediante a sua arualizaçăo, dc acordo com a nova classificaçāo dos funcionários em atividade, decomente da aplicaçāo desta I ci

Art. 39 - Ficam extintos os atuais cargos em comissão, funçōes de confiança e assemelhados nāo absorvidos pelos planos de carreira de que trata csta Lei.

Arr. 40 - O disposto nesta Lei nāo se aplica aos membros de Poderes Legislativo, Judiciário, Tribunal de Contas da Uniāo e Ministério Público da I Jniāo.

Art. 41 - O Poder Exccutivo expedirá o regulamento para execuçāo desta I ei, no prazo de noventa dias.

Art. 42 - Os brgäos ou entidades apresentarāo suas propostas de planos de carreira no prazo de até cento c nitenta dias, contados a partir da regulamentaçăo destal lei.

Ar1. 43 - Revogam-se a Lei n² 5.645, de 10 de dezembro de 1970 e demais disposiçōes em contrário.

Brasítia, IJF, de de de 1989; 168: da lndependência e 1010 da República. 